\title{
Dual task in healthy elderly, depressive and Alzheimer's disease patients
}

\author{
Dupla tarefa em idosos saudáveis, depressivos e \\ pacientes com doença de Alzheimer \\ José Vinícius Ferreira' \\ https://orcid.org/0000-0002-5025-7483 \\ Narahyana Bom de Araujo \\ https://orcid.org/0000-0003-1574-5075 \\ Felipe de Oliveira? \\ https://orcid.org/0000-0002-1457-0480 \\ Jéssica Plácido \\ https://orcid.org/0000-0003-1921-6672 \\ Paula Sant' Anna \\ https://orcid.org/0000-0003-3306-0336 \\ Renato Sobral Monteiro-Junior ${ }^{2}$ \\ https://orcid.org/0000-0002-8472-262X \\ Valeska Marinho' \\ https://orcid.org/0000-0003-4665-9655 \\ Jerson Laks' \\ https://orcid.org/0000-0002-5129-9087 \\ Andrea Deslandes ${ }^{1}$ \\ https://orcid.org/0000-0001-5941-9111
}

\section{Keywords}

Cognitive function, dual task, Alzheimer's disease, depression, functional capacity.

\section{ABSTRACT}

Objective: To investigate whether the DT performance can be affected by the diagnosis of major depressive disorder (MDD) and Alzheimer's disease (AD). Methods: Cross-sectional data with 108 individuals [Healthy $(H E)=56, M D D=19, A D=33$ ] aged 60 and older of both sexes diagnosis with $A D, M D D$, and HE without a clinical diagnosis of mental disorders, residents of the city of Rio de Janeiro. DT performance, was measured by mean velocity $(\mathrm{m} / \mathrm{s})$, DT cost and the number of evoked words (DT animals. One-way ANOVA was used to compare groups. In addition, a logistic regression was used to verify the association between the performance in the DT variables and the risk of MD and AD, controlled by age and scholarity. Results: There was a significant difference between the HE and AD groups in the DT variables. The worst performance in the DTC and DT animals $_{\text {variables increased risk of } A D \text {, regardless }}$ of age and scholarity (DTC, $O R=5.6,95 \% \mathrm{Cl}=1.4-22.2, \mathrm{p}=0.01$ and $\mathrm{DT}_{\text {animals' }} \mathrm{OR}=3.6,95 \% \mathrm{Cl}$ $=0.97-14.0, p=0.05)$. Conclusion: The ability to perform two tasks simultaneously appears to be impaired in patients with Alzheimer's disease, and unaffected by the major depressive disorder.

1 Federal University of Rio de Janeiro, Institute of Psychiatry, Rio de Janeiro, RJ, Brazil.

2 Montes Claros State University, Minas Gerais, MG, Brazil. 


\section{RESUMO}

Objetivo: Avaliar o quanto o desempenho em dupla tarefa pode ser afetado pelo diagnóstico do transtorno depressivo maior (TDM) e pela doença de Alzheimer (DA). Métodos: Estudo de corte transversal com 108 indivíduos [Saudáveis (IS) $=56, \mathrm{TDM}=19, \mathrm{DA}=33$ ] com 60 anos ou mais, de ambos os sexos, diagnosticados com doença de Alzheimer, transtorno depressivo maior e sem diagnóstico de doenças mentais, residentes na cidade do Rio de Janeiro. O desempenho em DT foi avaliado pela velocidade média $(\mathrm{m} / \mathrm{s})$, custo da dupla tarefa (CDT) e número de animais evocados por segundo ( $\left(\mathrm{T}_{\text {animais }}\right.$ ). ANOVA one-way foi feita para a comparação dos grupos. Além disso, foi utilizada uma regressão logística para verificar a associação entre o desempenho nas variáveis em DT e o risco de TDM e DA, controlado pela idade e escolaridade. Resultados: Houve diferença significativa entre os grupos IS e DA

\section{Palavras-chave}

Função cognitiva, dupla tarefa, doença de Alzheimer, depressão, capacidade funcional. nas variáveis em DT. O pior desempenho no CDT e no número de animais evocados em DT aumentou o risco de DA, independentemente da idade e escolaridade (CDT, OR =5,6, IC de $95 \%=1,4-22,2, p=0,01$ e DT animals' $^{\prime} \mathrm{OR}=3,6, \mathrm{IC}$ de $\left.95 \%=0,97-14,0, \mathrm{p}=0,05\right)$. Conclusão: $\mathrm{A}$ capacidade de realizar duas tarefas de forma simultânea parece ser prejudicada em pacientes com doença de Alzheimer e não afetada em pacientes com TDM.

\section{INTRODUCTION}

Major depressive disorder (MDD) and Alzheimer's disease (AD) are highly prevalent in the elderly, and there is a bidirectional relationship between them, since MDD may be a risk factor for $A D$, but the inverse pattern could also occur and vice versa', since areas such as prefrontal cortex and hippocampus are affected in both diseases ${ }^{2,3}$. According to Butters et al. ${ }^{4}$, this relationship can be explained by different ways: 1) HPA axis dysregulation that leads to increased cortisol levels, leading to hippocampal atrophy; 2 ) ischemic damage in the frontal-striatal regions. In addition, Kessing and Andersen ${ }^{5}$ found that the higher the number of episodes of major depression, increase the chance of this patient progress to a diagnosis of dementia. In Brazil, MDD has a prevalence of $7 \%{ }^{6}$ and more than half of the Brazilians identified with dementia are diagnosed with $A D^{7}$, establishing a major economic impact on the lives of these individuals and their families ${ }^{8,9}$. According to Araujo et $a . .^{10}$, a decreasing cognition gradient is observed when comparing healthy elderly, elderly with depression, patients with $A D$ and elderly people with $A D$ and MDD in comorbidity, wherein the relationship between the decline of cognitive functions and progress of both diseases is already well-established.

As a result, there has been a mounting interest in evaluation ways that are able to recognize $A D$ and MDD, and efforts to find tests which lead to early recognition of both diseases ${ }^{11-14}$. Tests using an individual's ability to perform two simultaneous tasks, named dual task (DT) have been used to address functional independence in a more naturalistic way. Gait analysis combined with a cognitive or motor task is one of the most used procedure. DT has been based on the hypothesis that when performing two tasks at the same time, in which similar neurofunctional circuits are recruited, an interference between them will be caused, resulting damages in the performance of one or both tasks ${ }^{15}$. Recently, the DT test was chosen to make the base battery for the assessment shared of mobility and cognition from the Canadian Consortium on Neurodegeneration in Aging (CCNA) and was considered sensitive to evaluate motor and cognitive changes, as well as being applicable in research and clinical practice ${ }^{16}$.

Interference between simultaneous tasks has been observed in the gait of the young, the elderly, and patients with different diseases ${ }^{17-20}$. In addition, there is an association of a better gait performance in DT with different health parameters, such as the lower risk of falls in individuals with a better gait performance in DT, as well as the relationship between more active individuals and a better velocity in $D^{21,22}$. Likewise, DT tests has been suggested to evaluate cognition due to lower influence of educational level ${ }^{23}$. Lastly, comparisons between Health Elderly and those with neuropsychiatric diseases, such as MDD and AD, have been studied ${ }^{24-26}$, being increasingly suggested the use of DT walking tests as a way of early identifying the signs of these diseases. Recently, Montero-Odasso et al. ${ }^{27}$ concluded that elderly with mild cognitive impairment (MCl) with a high DT cost (>20\%) are more likely to progress to dementia. Metzger et al. ${ }^{26}$ compared four groups: acute depressed plus cognitively mildly impaired, acute depressed, cognitively mildly impaired and health control, and found that health control group was the fastest in DT tests in comparison to other groups.

Based on the fact that MDD and AD are high prevalent diseases in the elderly, and both are related to a decline of physical and cognitive functions, the present study aimed to investigate Dual Task performance in elderlies with MDD and AD. Our hypothesis is that subjects with AD present a worse performance in every DT variables in comparison to HE subjects. 


\section{METHODS}

A cross-sectional study designed to compare the performance in DT of subjects who are healthy, depressed, and with Alzheimer's. The sample consisted of individuals aged 60 and older of both sexes diagnosed with AD, MDD, and $\mathrm{HE}$ without a clinical diagnosis of mental disorders, residents of the city of Rio de Janeiro. The AD diagnostic evaluation occurred according to DSM-IV ${ }^{28}$ and to NINCDSADRDA $^{29}$, including mild or moderate degrees according to Clinical Dementia Rating $(C D R)^{30}$. Patients with MDD were also diagnosed with DSM-IV criteria. Patients with mild to moderate MDD were included according to the Brazilian version of the Hamilton Depression Scale ${ }^{31}$. The elderly diagnosed with $A D$ and MDD were being treated at the Center for Alzheimer's Disease and other Disorders of Old Age at the Institute of Psychiatry of the Federal University of Rio de Janeiro. Health elderlies were all those who did not present diagnostic criteria for both diseases. Elderly who are illiterate or with a physical comorbidity that made it impossible to perform tests were excluded, as well as older people diagnosed with depression in a remission state or score $\geq 25$ points in Hamilton Scale (HDRS) for MDD and subject classified as CDR 3 according to the Clinical Dementia Rating (CDR) for AD. All those evaluated completed a medical history and performed physical, cognitive, dual task tests and anthropometric measurements [body mass index (BMI)], and signed the written informed consent form, and had access to all relevant research information and the main researcher's contact information. The evaluations were carried out on two distinct days and they lasted approximately 1 hour. The study was approved by the Research Ethics Committee at IPUB-UFRJ, under the following CAAE registration number: 24904814.0.0000.5263, and is part of the main research project titled "Efficacy of physical exercise in the treatment of major depression, Alzheimer's Disease, and Parkinson's Disease", wich was registered under the Brazilian Registry of Clinical Trials (REBEC) protocol RBR-4M3K2C.

\section{Mini Mental State Exam}

The MMSE was used to evaluate the general cognitive state, analyzing capacities of orientation (spatial and temporal), attention, concentration, memory, calculation, and language $\mathrm{e}^{32,33}$.

\section{Physical function}

To evaluate physical capacity of the elderly, three tests were used: 1) 30 seconds chair stand test, which evaluates the lower body muscle strength, requiring the individual to perform the highest number of full stands in 30 seconds $^{34}$; 2) 2 minutes Step test, which evaluates the cardiovascular endurance, the evaluated individual should elevate each knee to a point midway between the patella and the iliac crest ${ }^{34}$; 3$) 8$ foot up and go test which aims to evaluate the agility and dynamic balance, requiring to get up from seated position, walk 8 foot, turn, and return to seated position on chair ${ }^{34}$.

\section{Dual task analysis}

The DT test used was a combination of the 8 foot up and go test and the verbal fluency test. The subjects should perform the 8 foot up and go test with the maximum possible efficiency in the shortest possible time while evoking the highest number of animals they could. The instructions were as follow: "Please walk as fast as you can, do not run, and evoke the highest number of animals you could". For DT performance analysis, the mean velocity in the 8 foot up and go test in DT (DT m/s), the dual task cost (DTC), which was calculated by the formula (DTC $=$ ([time of the test in a single task - time of the test in a dual task] / time of the test in a single task) $\times 100$ ), and the number of the animals named per second during the performance of the 8 foot up and go ( $\left(\mathrm{DT}_{\text {animals }}\right)$. To determine the cut-off points of the variables in DT, the $25^{\text {th }}$ and $75^{\text {th }}$ percentile values found in the sample were used as classification criteria. Thus, performances $\leq 25^{\text {th }}$ percentile, between 26 75 , and $>75$, were classified as below normal, normal, and above normal, respectively.

\section{Statistical analysis}

To verify the normality of the data, the KomolgorovSmirnov analysis was used. To compare the groups $\left(A D_{\text {mild' }} A D_{\text {moderate' }} M D D\right.$, and $\left.H E\right)$, one-way ANOVA and a Bonferroni post-hoc test for comparison between group pairs in the variables that presented normal curves were performed. For the variables that did not present normal curves, the Kruskal-Wallis and the Mann-Whitney $U$ analysis were used. To verify if the MDD and the AD groups were clinically different from the HE group the effect size calculation in DT variables was used (effect size $=\mathrm{ES})^{35}$. Finally, with the aim of analyzing the chance of elderly individuals with different diagnoses presenting a worse performance in the variables in DT, a multinomial logistic regression was performed. For logistic regression analysis, DT performance was used as independent variables, all of which were categorized into three outcomes (Performance $\leq 25^{\text {th }}$ percentile, Performance between the $26^{\text {th }}$ and $75^{\text {th }}$ percentile, and Performance $>75^{\text {th }}$ percentile) and the different diagnoses were used as dependent variables. Secondly, the same predictive model was adjusted for age and education in order to verify whether these variables could influence the result. The statistical program SPSS version 20 was used for data analysis and the accepted significance level was $p \leq 0.05$. The sample size calculation was performed and found that the sample had an observed power $>80 \%(\beta=0.99)$, thus having external validity. 


\section{RESULTS}

The sample consisted of 189 subjects, 81 subjects being excluded for different reasons, totaling 108 older people divided into three groups, $56 \mathrm{HE}, 19$ diagnosed with major depression disorder (MDD) at a moderate stage (HDRS = $16.92 \pm 4.60$ ) and 33 with Alzheimer's disease (AD) (22 with $A D_{\text {mild }}$ and 11 with $A D_{\text {moderate }}$ ). Figure 1 shows the recruitment description of subjects. Table 1 shows that the $A D_{\text {mild }}$ group was slightly older, with a significant difference compared to the HE group $(U=334.00, p=0.002)$ and MDD group $(U=$ 108.50, $p=0.008$ ), and they had a lower educational level compared to the HE group $(U=310.00$ and $p=0.001)$. The AD group, as expected, presented a worse performance and a significant difference in MMSE compared to the HE ( $p<$ $0.001)$ and MDD groups $(p<0.001)$.
It was possible to observe a lower limb strength and agility and mobility above the cut-off point for risk of functional loss in the MDD and AD groups, evaluated by the "Sit Chair Stand test" and "8 foot Up and Go test", respectively. In the "Step 2 minutes test", only the HE group presented a performance above the cut-off point for risk of functional loss, while the other groups presented a performance below the cut-off point. Significant differences between the groups in " 8 foot Up and Go test" ( $X^{2}=10.43$ e $\left.p=0.015\right)$, and "2 minutes Step test" $(F=3.22$ e $p=0.026)$ were observed, and in the " 8 foot Up and Go" test only the mild and moderate AD groups were significantly different from the HE group (HEX AD mild $U=$ 379.00; $p=0.008$; HE $X$ AD moderate $U=162.00 ; p=0.013$ ). Table 1 shows the characteristics of the sample.

Differences were observed among groups in the mean velocity $(\mathrm{m} / \mathrm{s})(\mathrm{F}=11.09 ; \mathrm{p}<0.001)$, in the DTC $\left(X^{2}=22.35\right.$;

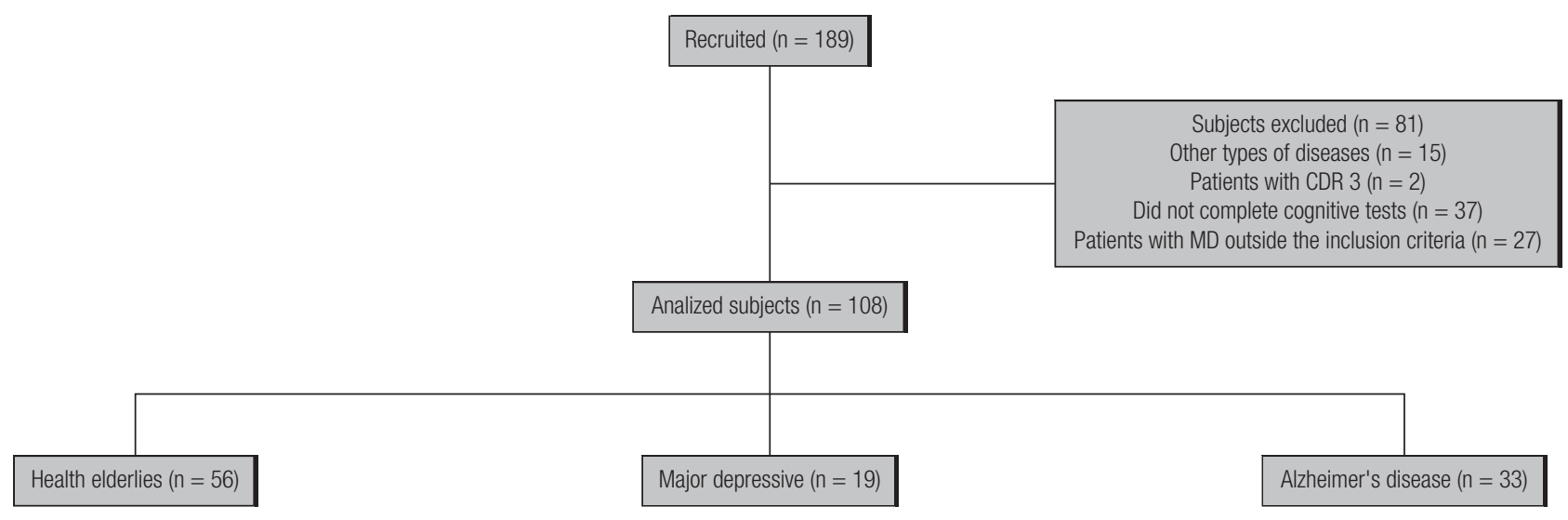

Figure 1. Fluxogram of sample recruitment.

Table 1. Clinical characteristics of the patients

\begin{tabular}{|c|c|c|c|c|c|c|}
\hline & HE $(n=56)$ & $\operatorname{MDD}(n=19)$ & $\operatorname{AD}$ Mild $(n=22)$ & AD Moderate $(n=11)$ & $F / X^{2}$ & $\mathrm{p}$ \\
\hline Age (years)* & $68.50(60-93)$ & $67.00(60-88)$ & $75.00(64-80)$ & $73.00(60-80)$ & 11.81 & $0.008^{\mathrm{a}, \mathrm{c}}$ \\
\hline Education (years)* & $12.50(1-29)$ & $11.00(4-20)$ & $7.50(3-22)$ & $12.00(2-16)$ & 13.32 & $0.004^{\mathrm{a}, \mathrm{c}}$ \\
\hline $\operatorname{BMI}\left(\mathrm{kg} / \mathrm{m}^{2}\right)^{*}$ & $25.52(20-40)$ & $25.74(20-33)$ & $24.84(19-38)$ & $24.07(19-29)$ & 2.4 & ns \\
\hline HAM -D & - & $16.92(4.60)$ & - & & & \\
\hline \multicolumn{7}{|l|}{ Cognitive Variables } \\
\hline MMSE (Score)* & $29.00(22-30)$ & $29.00(22-30)$ & $22.50(17-28)$ & $19.00(11-22)$ & 62,00 & $<0.001^{a, b, c, d, e}$ \\
\hline Verbal Fluency (number of animals) & $17.66 \pm 4.25$ & $16.16 \pm 3.57$ & $11.90 \pm 4.90$ & $9.82 \pm 4.64$ & 16,00 & $<0.001^{a, b, c, d}$ \\
\hline Stroop Test points (Score) ${ }^{*}$ & $16.00(11-35)$ & $15(11-21)$ & $24.31(13-53)$ & $35.55(19-61)$ & 34.15 & $<0.001^{a, b, c, d}$ \\
\hline Trails A (sec)* & $53.00(22-169)$ & $46.18(37-94)$ & $104.08(50-181)$ & $131.00(59-181)$ & 27.25 & $<0.001^{\mathrm{a}, \mathrm{b}, \mathrm{c}, \mathrm{d}}$ \\
\hline Digit Spam backward (Score) & $5.00(2-10)$ & $3.50(2-12)$ & $3.50(2-6)$ & $3(0-8)$ & 12.27 & $0.007^{\mathrm{a}, \mathrm{b}}$ \\
\hline \multicolumn{7}{|l|}{ Physical Function Variables } \\
\hline Sit Chair Stand (rep)* & $12(8-21)$ & $11(8-18)$ & $11(8-18)$ & $12(7-17)$ & 6.84 & ns \\
\hline 8 foot up and go (sec)* & $6.10(4-9)$ & $6.70(4-15)$ & $7.13(4-16)$ & $6.91(6-19)$ & 10.43 & $0.015^{a, b}$ \\
\hline 2 min Step (rep) & $78.66 \pm 23.07$ & $62.33 \pm 30.72$ & $64.11 \pm 24.04$ & $62.09 \pm 31.25$ & 3.22 & 0.026 \\
\hline
\end{tabular}

* Non-parametric variables described in median, minimum and maximum values.

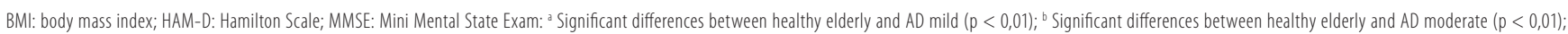

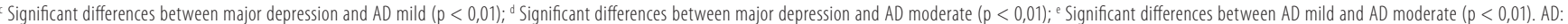
Alzheimer disease; MDD: major depressive disorder; HE: healthy elderly. 
$p<0,001)$, and in $D T_{\text {animals }}(F=11.56 ; p<0,001)$. The AD group presented a worse performance regardless of staging in comparison to the HE group in the three variables analyzed $(p<0.001)$. When comparing between the MDD and AD groups, only the $A D_{\text {moderate }}$ group presented a significant difference in the three variables [mean velocity $(\mathrm{m} / \mathrm{s})(\mathrm{p}=$ 0.03), $\left.D T_{\text {animals }} p<0.001\right)$, and DTC $\left.(U=39.00, p=0.004)\right]$, while the $A D_{\text {mild }}$ group presented a significant difference only in DTC $(U=123.00, p=0.025)$. The results of the comparison of DT variables in the different groups are presented in table 2.

Effect size showed that the MDD group presented worse performance than HE group. Although the effect size small and moderate was observed in the three DT variables (mean velocity $\left.(\mathrm{m} / \mathrm{s}), d=-0.39 ; D T C, d=-0.57 ; D_{\text {animals }} d=-0.20\right)$ in $M D D$, large clinical differences $\left(A D_{\text {mild }}\right.$; mean velocity $(\mathrm{m} / \mathrm{s})$, $\left.d=-1.19 ; D T C, d=-1.12 ; D T_{\text {animals' }} d=-0.81\right)$ and $\left(A_{\text {moderate }}\right.$; $\mathrm{DT}(\mathrm{m} / \mathrm{s}), \mathrm{d}=-1.49 ; \mathrm{DTC}, \mathrm{d}=-1.81 ; \mathrm{DT}_{\text {animals' }} \mathrm{d}=-1.86$ ) were observed in the $A D_{\text {mild }}$ and $A D_{\text {moderate }}$ groups (Figure 2).

Table 3 shows the results of the logistic regression analysis. By dividing groups into three classifications, it was possible to observe that a performance below the 25th percentile did not increase risk of MDD compared to the HE group. However, a performance below this percentile in the DTC increased risk of AD diagnosis in 3.6 times $(O R=$
3.6, $95 \% \mathrm{Cl}=1.04-12.67, \mathrm{p}=0.042$ ), while in the $\mathrm{DT}_{\text {animals }}$ the probability increased to 4.2 times $(\mathrm{OR}=4.2 ; 95 \% \mathrm{Cl}=1.14$ $15.56 ; p=0.031)$. A performance below the $25^{\text {th }}$ percentile in the mean velocity $(\mathrm{m} / \mathrm{s})$ variable did not increase risk of $A D$. These results remained after adjusted by age and scholarity $\left(\mathrm{DT}_{\text {animals }} ; \mathrm{OR}=3.6 ; 95 \% \mathrm{Cl}=0.97-14.0 ; \mathrm{p}=0.05\right.$ and $\mathrm{DTC} ; \mathrm{OR}=$ 5.6; $95 \% \mathrm{Cl}=1.4-22.2 ; \mathrm{p}=0.01$ ).

\section{DISCUSSION}

The present study aimed to compare the DT performance among healthy, MDD and AD elderlies. In addition, we analyzed the chance of elderly individuals with worse performance in DT parameters presenting a diagnosis of $A D$ or MDD.

As expected, mild and moderate AD presented a worse performance in DT compared to healthy older adults and the impairment in DT was associated with the severity of disease. Our results, corroborate the study from Beauchet et al. ${ }^{36}$, that verified an association between the increase of the severity of cognitive impairments with a decrease of different gait parameters. A possible explanation is the relationship between the performance in different subfunctions

Table 2. Comparison of performance in dual task between groups

\begin{tabular}{|c|c|c|c|c|c|c|}
\hline & HE $(n=56)$ & $\operatorname{MDD}(n=19)$ & AD Mild ( $n=22)$ & AD Moderate $(n=11)$ & $F / X^{2}$ & $p$ \\
\hline Dual Task (m/s) & $0.68 \pm 0.12$ & $0.61 \pm 0.21$ & $0.49 \pm 0.22$ & $0.43 \pm 0.11$ & 11.09 & $<0.001^{b, c, e}$ \\
\hline Number of animals (animals per second) & $0.85 \pm 0.30$ & $0.79 \pm 0.29$ & $0.59 \pm 0.32$ & $0.32 \pm 0.18$ & 11.56 & $<0.001^{b, c, e}$ \\
\hline Dual Task Cost (\%)* & $-16.71(-63.89-8.92)$ & -15.16 (-169.19-10.07) & $-39.98(-196.28-5.39)$ & $-39.39(-138.95-18.08)$ & 22.35 & $<0.001^{b, c, d, e}$ \\
\hline
\end{tabular}

${ }^{*}$ Non-parametric variables described in median, minimum and maximum values. ${ }^{\circ}$ Significant differences between healthy elderly and AD mild $(p<0,01) ;{ }^{c}$ Significant differences between healthy elderly and AD moderate ( $\left.p<0,01\right)$;

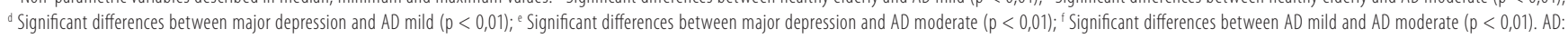
Alzheimer disease; MDD: major depressive disorder; HE: healthy elderly.

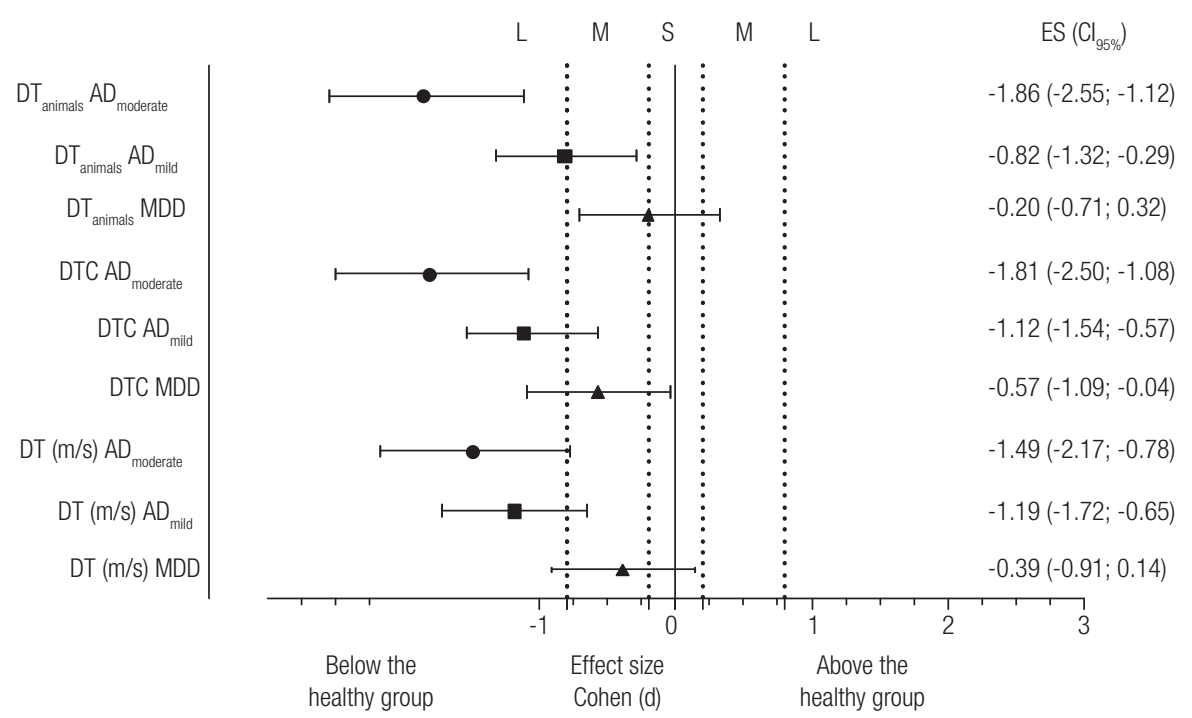

Figure 2. Effect size of the DT variables of the MDD and AD groups. The reference values used are the mean values of the DT variables (DT(m/s), DT $T_{\text {animals }}$ and DTC) found in HE group. S = Small (<0.20); M = Moderate (0.21-0.80); $L=L a r g e(00.80)$. 
associated with executive functions (EF) and the performance of $\mathrm{DT}^{19,37,38}$ and by the association between divided attention deficits and metabolic dysfunction of right frontal and parietal lobes in AD patients ${ }^{39}$. These findings reinforce theories that consider DT as a way of assessing the ability of the brain to divide attention. In this sense, Beauchet et al. ${ }^{11}$ suggested the use of DT tests by combining gait with a second task as a way to evaluate an early dementia diagnosis. In the present study, the AD group presented a worse performance in all DT variables compared to the other two groups, in addition to presenting a worse clinical performance compared to the healthy group thus corroborating the studies above. Our study suggests that the worse performance in DT seems to be associated with the cognitive impairment caused by AD. Another aspect that supports the hypothesis of a worse performance in DT being a clinical characteristic associated with patients with $A D$, is the increased chance of diagnosis with the presence of a performance below the 25th percentile being only observed in this group.

DT performance was not affected by MDD. The similar performance of MDD and HE groups in performing the dual task can be explained by a similar global cognitive performance assessed by the MMSE, besides presenting preserved physical capabilities. The performance of activities in DT requires a greater activation of brain areas when compared to a single task, mainly in the prefrontal cortex ${ }^{17}$, which demands that these areas are preserved. Even in elderly diagnosed with depression, cognitive and physical functions were not impaired by the disease, to the point of clinically and significantly interfering in the ability of performing tasks in DT. Another point to note is that all patients diagnosed with depression used selective serotonin reuptake inhibitors (SSRIs). Paleacu et al. ${ }^{40}$ showed that SSRIs, besides reducing depressive symptoms, were also able to increase the distance covered by approximately 13.2 meters in the test that evaluated gait performance. The results found in the present study partially corroborate, which found a significant difference between depressed and nondepressed elderlies only in DTC and in DT tests with greater complexity. Moreover, Radovanović et al..$^{41}$ found changes in few gait variables (gait cycle time and double support time) of depressive patients, and they also observed a prioritization of attention to gait during the more complex task (gait + subtraction of $7+$ carrying a tray with a glass of water). It is possible that the relatively simple DT protocol used in the present study did not generate an enough cognitive demand to impair performance in MDD patients. This study has some important limitations. The cross-sectional design did not allow the stablishment of cause-effect interferences in DT variables. Another point that can be considered a limitation of the study is the fact that the sample is part of a group that intended to receive treatment and may somehow influence the outcome of the study. We suggest in future studies, it was also investigated CDT related cognitive task, as this could increase the understanding of the behavior of $A D$ patients during testing in DT.

Table 3. Association between DT performance and major depressive disorder and Alzheimer disease diagnosis

\begin{tabular}{|c|c|c|c|c|c|c|c|c|c|c|c|c|}
\hline & MDD & & & $A D$ & & & $M D D^{+}$ & & & $A D^{+}$ & & \\
\hline & OR & $(95 \% \mathrm{Cl})$ & $p$ & OR & $(95 \% \mathrm{Cl})$ & $\mathrm{p}$ & $O R$ & $(95 \% \mathrm{Cl})$ & $\mathrm{p}$ & $O R$ & $(95 \% \mathrm{Cl})$ & $\mathrm{p}$ \\
\hline \multicolumn{13}{|l|}{ DT (m/s) } \\
\hline $\begin{array}{l}\text { Between the } 25^{\text {th }} \\
\text { and } 75^{\text {th }} \text { percentile }\end{array}$ & 1 & & & 1 & & & 1 & & & 1 & & \\
\hline $\begin{array}{l}\text { Below the } 25^{\text {th }} \\
\text { percentile }\end{array}$ & 0.73 & $(0.18-3.0)$ & 0.67 & 3.2 & $(0.86-11.83)$ & 0.08 & 0.55 & $(0.11-2.5)$ & 0.45 & 1.7 & $(0.41-7.7)$ & 0.43 \\
\hline $\begin{array}{l}\text { Above the } 75^{\text {th }} \\
\text { percentile }\end{array}$ & 0.27 & $(0.02-2.6)$ & 0.26 & 0.87 & $(0.11-6.6)$ & 0.9 & 0.23 & $(0.02-2.3)$ & 0.21 & 0.83 & $(0.09-7.0)$ & 0.87 \\
\hline \multicolumn{13}{|l|}{ DT Animals } \\
\hline $\begin{array}{l}\text { Between the } 25^{\text {th }} \\
\text { and } 75^{\text {th }} \text { percentile }\end{array}$ & 1 & & & 1 & & & 1 & & & 1 & & \\
\hline $\begin{array}{l}\text { Below the } 25^{\text {th }} \\
\text { percentile }\end{array}$ & 0.51 & $(0.12-2.1)$ & 0.35 & 4.2 & $(1.14-15.56)$ & $0.03^{*}$ & 0.47 & $(0.11-2.0)$ & 0.32 & 3.6 & $(0.97-14,0)$ & $0.05^{*}$ \\
\hline $\begin{array}{l}\text { Above the } 75^{\text {th }} \\
\text { percentile }\end{array}$ & 0.21 & $(0.02-2.0)$ & 0.17 & 1.9 & $(0.29-12.5)$ & 0.48 & 0.26 & $(0.02-2.5)$ & 0.24 & 2.1 & $(0.30-15.3)$ & 0.43 \\
\hline \multicolumn{13}{|l|}{ DTC } \\
\hline $\begin{array}{l}\text { Between the } 25^{\text {th }} \\
\text { and } 75^{\text {th }} \text { percentile }\end{array}$ & 1 & & & 1 & & & 1 & & & 1 & & \\
\hline $\begin{array}{l}\text { Below the } 25^{\text {th }} \\
\text { percentile }\end{array}$ & 1.6 & $(0.40-6.4)$ & 0.49 & 3.6 & $(1.04-12.6)$ & $0.04^{*}$ & 1.9 & $(0.42-8.7)$ & 0.39 & 5.6 & $(1.4-22.2)$ & $0.01^{*}$ \\
\hline $\begin{array}{l}\text { Above the } 75^{\text {th }} \\
\text { percentile }\end{array}$ & 1.15 & $(0.27-4.9)$ & 0.84 & 1.3 & $(0.19-8.7)$ & 0.77 & 1.2 & $(0.27-5.4)$ & 0.84 & 1.6 & $(0.23-11.5)$ & 0.62 \\
\hline
\end{tabular}

DT (m/s): mean velocity in DT; DTC: dual task cost; DT animals: number of animals evoked in DT; MD: major depressive; AD: Alzheimer disease. * Significant result. $\mathbf{T}$ Adjust by age and scholarity. 


\section{CONCLUSION}

In conclusion, the ability to perform two tasks simultaneously appears to be impaired in patients with Alzheimer's disease, and unaffected by the Major Depression.

\section{INDIVIDUAL CONTRIBUTIONS}

\section{José Vinícius Ferreira, Narahyana Bom de Araujo} and Andrea Deslandes - Contributed to conception and design of data. Msc.

José Vinícius Ferreira, Felipe de Oliveira, Jéssica Plácido, Paula Sant' Anna, Renato Sobral MonteiroJunior, Valeska Marinho, Jerson Laks and Andrea Deslandes - Contributed to revising it critically for important intellectual content. All authors reviewed and had given the final approval of the version to be published.

\section{CONFLICT OF INTERESTS}

All authors declare none conflict of interest. This research project was registered under the Brazilian Registry of Clinical Trials (REBEC) protocol RBR-4M3K2C.

\section{ACKNOWLEDGMENT}

We thank the following funding agencies: Conselho Nacional de Desenvolvimento Científico e Tecnológico (CNPq301483/2016-7), Fundação de Amparo à Pesquisa do Estado do Rio de Janeiro (Faperj-E26/203.193/2016).

\section{REFERENCES}

1. Starkstein SE, Jorge R, Mizrahi R, Robinson RG. The construct of minor and major depression in Alzheimer's disease. Am J Psychiatry. 2005;162(11):2086-93.

2. Raskin J, Cummings J, Hardy J, Schuh K, A Dean R. Neurobiology of Alzheimer's disease: integrated molecular, physiological, anatomical, biomarker, and cognitive dimensions. Curr Alzheimer Res. 2015;12(8):712-22.

3. Maletic V, Robinson M, Oakes T, lyengar S, Ball S, Russell J. Neurobiology of depression: an integrated view of key findings. Int J Clin Pract. 2007;61(12):2030-40.

4. Butters MA, Young JB, Lopez O, Aizenstein HJ, Mulsant BH, Reynolds CF 3rd, et al. Pathways linking late-life depression to persistent cognitive impairment and dementia. Dialogues Clin Neurosci. 2008;10(3):345-57.

5. Kessing LV, Andersen PK. Does the risk of developing dementia increase with the number of episodes in patients with depressive disorder and in patients with bipolar disorder? J Neurol Neurosurg Psychiatry. 2004;75(12):1662-6.

6. Barcelos-Ferreira R, Izbicki R, Steffens DC, Bottino CM. Depressive morbidity and gender in community-dwelling Brazilian elderly: systematic review and meta-analysis. Int Psychogeriatr. 2010;22(05):712-26

7. Herrera Jr E, Caramelli P, Silveira ASB, Nitrini R. Epidemiologic survey of dementia in a community-dwelling Brazilian population. Alzheimer Dis Assoc Disord. 2002;16(2):103-8.
8. Chisholm D, Sweeny K, Sheehan P, Rasmussen B, Smit F, Cuijpers P, et al. Scaling-up treatment of depression and anxiety: a global return on investment analysis. Lancet Psychiatry. 2016;3(5):415-24.

9. Prince M, Comas-Herrera A, Knapp M, Guerchet M, Karagiannidou M. World Alzheimer report 2016: improving healthcare for people living with dementia: coverage, quality and costs now and in the future. London, UK: Alzheimer's Disease International (ADI); 2016.

10. Araujo NB, Moraes HS, Silveira H, Arcoverde C, Vasques PE, Barca ML, et al. Impaired cognition in depression and Alzheimer (AD): a gradient from depression to depression in AD. Arqu Neuro-Psiquiatr. 2014;72(9):671-9.

11. Beauchet 0 , Allali $G$, Berrut G, Hommet C, Dubost V, Assal F. Gait analysis in demented subjects: Interests and perspectives. Neuropsychiatr Dis Treat. 2008;4(1A):155-60.

12. Lonie JA, Tierney KM, Herrmann LL, Donaghey C, O'Carroll RE, Lee A, et al. Dual task performance in early Alzheimer's disease, amnestic mild cognitive impairment and depression. Psychol Med. 2009;39(1):23-31.

13. Bossers WJ, Van der Woude LH, Boersma F, Scherder EJ, van Heuvelen MJ. Recommended measures for the assessment of cognitive and physical performance in older patients with dementia: a systematic review. Dement Geriatr Cogn Dis Extra. 2012;2(1):589-609.

14. Brandler TC, Wang C, Oh-Park M, Holtzer R, Verghese J. Depressive symptoms and gait dysfunction in the elderly. Am J Geriatr Psychiatry. 2012;20(5):425-32.

15. Allali G, Assal F, Kressig RW, Dubost V, Herrmann FR, Beauchet 0. Impact of impaired executive function on gait stability. Dement Geriatr Cogn Disord. 2008;26(4):364-9.

16. Montero-Odasso M, Almeida QJ, Bherer L, Burhan AM, Camicioli R, Doyon J, et al. Consensus on shared measures of mobility and cognition: from the Canadian Consortium on Neurodegeneration in Aging (CCNA). J Gerontol A Biol Sci Med Sci. 2019 May 1;74(6):897-909.

17. Holtzer R, Mahoney JR, Izzetoglu M, Izzetoglu K, Onaral B, Verghese J. fNIRS study of walking and walking while talking in young and old individuals. J Gerontol A Biol Sci Med Sci. 2011;66(8):879-87.

18. Wright SL, Kay RE, Avery ET, Giordani B, Alexander NB. The impact of depression on dual tasking among patients with high fall risk. J Geriatr Psychiatry Neurol. 2011;24(3):142-50.

19. Coelho FG1, Stella F, de Andrade LP, Barbieri FA, Santos-Galduróz RF, Gobbi S, et al. Gait and risk of falls associated with frontal cognitive functions at different stages of Alzheimer's disease. Neuropsychol Dev Cogn B Aging Neuropsychol Cogn. 2012;19(5):644-56.

20. Wittwer JE, Webster KE, Hill K. The effects of a concurrent motor task on walking in Alzheimer's disease. Gait Posture. 2014;39(1):291-6.

21. Glenn JM, Vincenzo J, Canella CK, Binns A, Gray M. Habitual and Maximal Dual-Task Gait Speeds among Sedentary, Recreationally Active, and Masters Athlete Late Middle-Aged Adults. J Aging Phys Act. 2015;23(3):433-7.

22. Muir-Hunter $S$, Wittwer J. Dual-task testing to predict falls in community-dwelling older adults: a systematic review. Physiotherapy. 2016;102(1):29-40.

23. Ansai JH, Aurichio TR, Rebelatto JR. Relationship between dual task walking, cognition, and depression in oldest old people. Int Psychogeriatr. 2016;28(1):31-8.

24. Nadkarni NK, Levine B, Mcllroy WE, Black SE. Impact of subcortical hyperintensities on dualtasking in Alzheimer disease and aging. Alzheimer Dis Assoc Disord. 2012;26(1):28-35.

25. Gabel NM, Crane NA, Avery ET, Kay RE, Laurent A, Giordani B, et al. Dual-tasking gait variability and cognition in late-life depression. Int J Geriatr Psychiatry. 2015;30(11):1120-8.

26. Metzger FG, Hobert MA, Ehlis AC, Hasmann SE, Hahn T, Eschweiler GW, et al. Dual tasking for the differentiation between depression and mild cognitive impairment. Front Aging Neurosci. 2016:8:235

27. Montero-Odasso MM, Sarquis-Adamson Y, Speechley M, Borrie MJ, Hachinski VC, Wells J, et al. Association of Dual-Task Gait With Incident Dementia in Mild Cognitive Impairment: Results From the Gait and Brain Study. JAMA Neurol. 2017;74(7):857-65.

28. American Psychiatric Association. DSM-IV: Manual de Diagnóstico e Estatística das Perturbações Mentais. 1996.

29. McKhann GM, Knopman DS, Chertkow H, Hyman BT, Jack Jr CR, Kawas CH, et al. The diagnosis of dementia due to Alzheimer's disease: recommendations from the National Institute on Aging-Alzheimer's Association workgroups on diagnostic guidelines for Alzheimer's disease. Alzheimer Dement. 2011;7(3):263-9.

30. Chaves MLF, Camozzato AL, Godinho C, Kochhann R, Schuh A, de Almeida VL, et al. Validity of the clinical dementia rating scale for the detection and staging of dementia in Brazilian patients. Alzheimer Dis Assoc Disord. 2007;21(3):210-7. 
31. Moreno R, Moreno D. Escalas de avaliação clínica em psiquiatria e psicofarmacologia: escalas de avaliação para depressão de Hamilton (HAM-D) e Montgomery-Asberg (MADRS). Rev Psiquiatr Clin (São Paulo). 1998;25(5):1-17.

32. Folstein MF, Folstein SE, McHugh PR. "Mini-mental state": a practical method for grading the cognitive state of patients for the clinician. J Psychiatr Res. 1975;12(3):189-98.

33. Bertolucci PH, Brucki S, Campacci SR, Juliano Y. 0 mini-exame do estado mental em uma população geral: impacto da escolaridade. Arq Neuropsiquiatr. 1994;52(1):1-7.

34. Rikli RE, Jones CJ. Senior fitness test. Champaign (IL): Human Kinetics; 2001.

35. Cohen J. Statistical power analysis for the behavioral sciences. Abingdon: Routledge; 2013.

36. Beauchet 0, Blumen HM, Callisaya ML, De Cock AM, Kressig RW, Srikanth V, et al. Spatiotemporal Gait Characteristics Associated with Cognitive Impairment: A Multicenter CrossSectional Study, the Intercontinental "Gait, cognition \& Decline" Initiative. Curr Alzheimer Res. 2018;15(3):273-82.
37. Sheridan PL, Solomont J, Kowall N, Hausdorff JM. Influence of executive function on locomotor function: divided attention increases gait variability in Alzheimer's disease. J Am Geriatr Soc. 2003;51(11):1633-7.

38. Zidan M, Arcoverde C, Araújo NB, Vasques P, Rios A, Laks J, et al. Alterações motoras e funcionais em diferentes estágios da doença de Alzheimer. Rev Psiquiatr Clin. 2012;39(5):161-5.

39. Nestor PG, Parasuraman R, Haxby JV, Grady CL. Divided attention and metabolic brain dysfunction in mild dementia of the Alzheimer's type. Neuropsychologia. 1991;29(5):379-87.

40. Paleacu D, Shutzman A, Giladi N, Herman T, Simon ES, Hausdorff JM. Effects of pharmacological therapy on gait and cognitive function in depressed patients. Clinical neuropharmacology. 2007;30(2):63-71.

41. Radovanović S, Jovičić M, Marić NP, Kostić V. Gait characteristics in patients with major depression performing cognitive and motor tasks while walking. Psychiatry Res. 2014;217(1):39-46. 